\section{English Series}

(C) The Editorial Office of AMS \& Springer-Verlag 2009

\title{
Erratum to: Existence of Positive Solutions for a Singular $p$-Laplacian Differential Equation
}

\author{
Li XIA \\ Department of Mathematics, Shenzhen University, \\ Shenzhen 518060, P. R. China \\ E-mail: xaleysherry@163.com \\ Zheng An YAO \\ Department of Mathematics, Zhongshan University, \\ Guangzhou 510275, P. R. China \\ E-mail:mcsyao@mail.sysu.edu.cn \\ Wen Shu ZHOU \\ Department of Mathematics, Jilin University, \\ Changchun 130012, P. R. China \\ E-mail:wolfzws@163.com
}

\section{Erratum to: Acta Mathematica Sinica, English Series DOI: $10.1007 / \mathrm{s} 10114-008-6238-9$}

The original version of this article unfortunately contained a mistake. The spelling of the first author's name was incorrect. The correct spelling is Li XIA. 